\title{
Typical Phrases For Shona Syntactic Subjecthood
}

\author{
Dr. Isaac Mhute \\ Zimbabwe Open University
}

doi: 10.19044/esj.2016.v12n5p340 URL:http://dx.doi.org/10.19044/esj.2016.v12n5p340

\begin{abstract}
This paper presents findings from a qualitative research that focused on providing a comprehensive description of the Shona subject relation. Shona is a Bantu language spoken by around $75 \%$ of the over 13 million people making up the Zimbabwean population plus the other speakers in neighbouring countries like Zambia, Botswana and South Africa. The paper reveals the types of phrases that typically perform the subject role in the language. The research concentrated mainly on the language as used by speakers of the dialect spoken by the Karanga people of Masvingo Province (the region around Great Zimbabwe) and the Zezuru dialect spoken by people of central and northern Zimbabwe (the area around Harare Province).
\end{abstract}

Keywords: Semantics, meaning, theories

\section{Introduction and Literature Review}

Syntax is a branch of linguistics focusing on the arrangement of words and their relationships in sentences (Crystal, 1969). Syntactic rules govern proper sentence structure. This study seeks to venture into the syntactic notion of grammatical relations focusing particularly on the Shona subject relation in a bid to come up with its detailed characterisation. Owens (2004) defines the term 'grammatical relations' as the relation between the head of a predicate and its argument phrases particularly subject and object in a sentence.

According to Guthrie (1948), Shona (or ChiShona) is a Bantu language, native to the Shona people of Zimbabwe and southern Zambia. The term is also used to identify peoples who speak one of the Shona language dialects, namely Zezuru, Karanga, Manyika, Ndau and Korekore following Clement Doke' s resolutions of 1931 (Mhute and Kadenge, 2014). According to Mutasa (1996), some researchers include Kalanga whilst others recognise it as a distinct language in its own right.

A subject is generally understood to be the syntactic argument acting on the object in a simple active sentence (Lee, 1974). For instance, in the 
following sentence:

1a. Mary apfura John.
$\begin{array}{lcccrr}\text { Mary } & \text { a- } & \text { pfur- } & \text { a } & \text { John } \\ \text { cl.1 } & \text { cl.1 AGR } & \text { VR 'kick' } & & \text { TV } & \text { cl.1 }\end{array}$
"Mary kicked John."

Mary is the subject as it volitionally initiates and carries out the action suffered by the object (John) on to its logical conclusion. Though there are various types of the subject relation in the language as demonstrated by Mhute and Kadenge (2014), this article upholds this as its working definition for the syntactic relation.

The core intention of this paper is to find out the types of lexical items to which the Shona subject relation is typically assigned. This includes testing other researchers' findings in Shona such as Langacker (1991) who points out that, in most languages a prototypical subject is a noun phrase. This position is supported by Everaert, van Riemsdijk and Goedemans (2006) who present the following typical examples of the subject noun phrases:

1. A determinerless noun phrase (NP), also called a bare noun phrase. This is mostly limited to plural NPs and NPs headed by a mass noun such as vavaki "builders" in example $1 \mathrm{~b}$ :

1b. Vavaki vari kushanda.

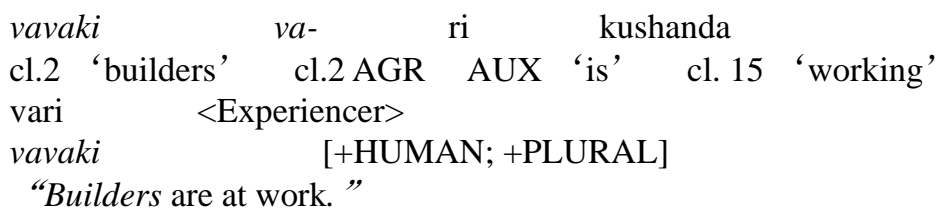

2. An NP introduced by a determiner. This complex (determiner + NP) is usually called a determiner phrase. In Shona there is no such a type though the English translation may have it as follows:

1c. Mota yamira.

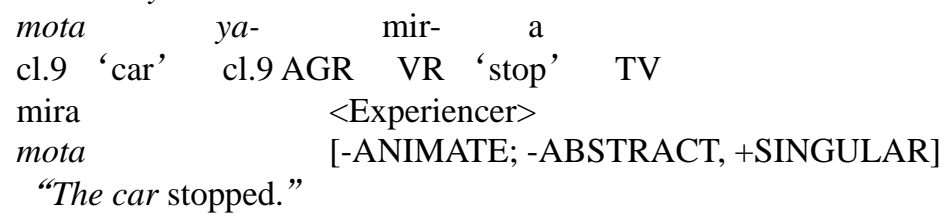

Mota "the car" is a determinerless Shona NP though English translation has a determiner.

\section{NPs and the Shona subject role}

As highlighted above, the typical trend in sentences is that NPs are assigned the subject role in most languages. A close consideration of the 
subjects for the examples already presented in this analysis, confirms the position to a considerable extent.

To further support the position consider more examples that are presented below. Firstly there are NPs consisting of pronouns and nouns in apposition as in:

1.d. Ivo vanhu varwira sadza.

$\begin{array}{lcccccc}\text { ivo } & v a-\text { nhu } & v a- & \text { rwir- } & \text { a } & \text { sadza } & \\ \text { cl.2 PRON } & \text { cl.2 'people' } & \text { cl.2AGR } & \text { VR } & \text { 'fight for' } & \text { TV } & \text { cl.5 }\end{array}$ 'sadza'

ivo vanhu

rwira

NP Subject ---------- pronoun + noun - qualifier

ivo vanhu

$<$ Agent Patient>

sadza

"They the people fought for sadza."

Ivo vanhu "they the people" is an NP with ivo "they" and vanhu "people" occurring as pronoun and noun in apposition.

One can also have a pronoun and noun in apposition plus a qualifier as in:

1e. Ivo vanhu venyu vaba doro.

ivo va- nhu venyu va- b- $\quad$ a doro

cl.5 'beer'

cl.2pron cl.2 'people' cl.2POSS cl.2AGR VR 'steal' TV

ivo vanhu venyu
$\begin{gathered}\text { NP Subject } \\ \text { vaba }\end{gathered}$
$<$ Agent Patient $>$

ivo vanhu venyu [+HUMAN, -SINGULAR]

doro

[-ANIMATE, -ABSTRACT]

"They your people stole beer."

The NP subject ivo vanhu venyu "they your people" is an NP that has the combination of a pronoun ivo "they" , noun vanhu "people" and possessive venyu "your" . This is an acceptable combination for an NP in Shona.

One can have a noun and adjectival qualifier as in:

1f. Mukadzi muroyi waba mwana.

mu- kadzi mu- royi wa- b- a mwana

cl.1 'woman' cl.1 'witch' cl.1AGR VR 'steal' $\quad$ TV $\quad$ cl.1 'child'

mukadzi muroyi NP Subject ---------- noun and adjective in apposition

waba <Agent Patient>

mukadzi muroyi [+HUMAN; +SINGULAR]

mwana [+HUMAN; +SINGULAR]

"A female witch stole a child."

The subject is an NP made up of a noun mukadzi "female" and an 
adjectival qualifier muroyi "witch" occurring in apposition. It is again an acceptable combination for a Shona NP.

One can also have a noun without a qualifier as in:

1.g Munya watora banga.

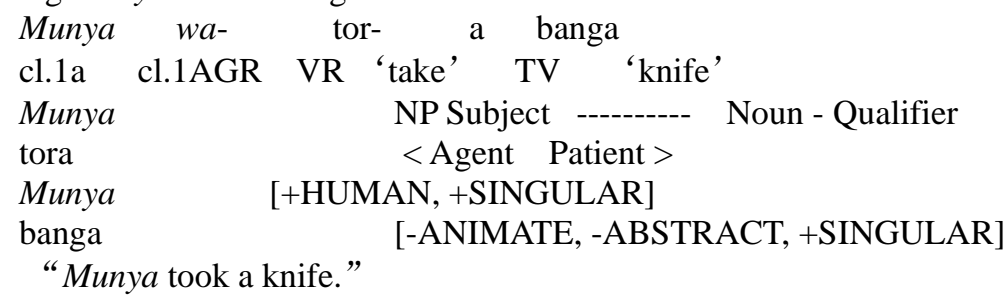

Munya is a noun acting as an NP subject. This demonstrates that, as highlighted earlier, NPs made up of nouns without qualifiers are also acceptable in Shona.

This is the general trend in most of the sentences making up the gathered data. Such a trend demonstrates that the subject role is typically assigned to the various NP types in the language. However, this is not always the case since one can also have non-NPs as subjects both in isolation and in combination as demonstrated in the next section.

\section{Non-NPs and the Shona subject role}

Consider the following Shona sentences:

1h. Imwe yaenda kumusha.

$\begin{array}{lllll}\begin{array}{l}\text { imwe } \\ \text { cl.9 'another one' }\end{array} \begin{array}{l}\text { cl.9AGR } \\ \text { cl.9R }\end{array} \text { 'go' } & \text { TV } & \text { CL.15 'home' } \\ \text { imwe } & \text { non-NP Subject } & -------- & \text { enumerative } \\ \text { enda } & \text { <Agent Goal> } \\ \text { imwe } & \text { [+ANIMATE; +SINGULAR] } \\ \text { kumusha } & \text { [-ANIMATE; -ABSTRACT] }\end{array}$

"Another one has gone home."

This is an acceptable Shona sentence with imwe "another one" an enumerative playing the subject role. It is not an NP. It can rather be regarded as an enumerative phrase of some sort. One can also have:

1i. Tsvuku yaguta doro.

$\begin{array}{llcccc}\text { tsvuku } & y a- & \text { gut- } & \text { a } & \text { doro } & \\ \text { cl.9 ADJ 'red one' } & \text { cl.9 AGR } & \text { VR 'be satisfied' } & \text { TV } & \text { cl.5 }\end{array}$
'beer'

$\begin{array}{lc}\text { tsvuku : } & \text { non-NP Subject } \\ \text { guta } & \text {---------- } \\ \text { tsvikueriencer } & \text { Source> } \\ \text { doro } & \text { [+ANIMATE; +SINGULAR] } \\ \text { "The red one has had enough beer." } & \text { [-ANIMATE; -ABSTRACT] }\end{array}$

This acceptable Shona sentence has an adjectival subject tsvuku "red 
one” acting as the subject.

$1 \mathrm{j}$. Iyi neiya ndedzangu.
iyi ne- iya
cl.9DEM. conj. Cl.9SEL. COPPL. POSS
iyi neiya
non-NP Subject combination
demonstrative +
selector
iyi neiya
[+ANIMATE; -SINGULAR]
"This one and that one are mine."

This is a sentence with a combination of a demonstrative and selector iyi neiya "this one and that one" . Nonetheless, it is also a grammatical and acceptable sentence.

It is worth pointing out that all these sentences with non NPs are only complete statements if looked at in their respective or known contexts. However, such sentences are often found in day-to-day speeches and this leaves one in a position to assert that not only NPs perform the subject role in Shona. By looking at the direct translations of the examples, one can realise that they are not strange to English. They often occur in day to day English conversations, which shows that such sentential subject structures are common to English as well. This is a position that supports Fortune' s (1959) assertion that constructions belonging to the constituent class of Shona subjects are substantive phrases, compound substantive phrases, and conjunctives plus substantive phrases, a statement that does not restrict the role exclusively to NPs.

It, however, needs to be reemphasised that such non-NPs whether in isolation or in combination make complete sense as subjects if and only if the referent subject is some piece of old information to the hearer. This serves to demonstrate that there would always be some covert nouns qualifying the non-NP substantives. The sentences are only acceptable as a result of the flexibility characterising the language in question. For instance, iyi neiya "this one and that one" in example $1 \mathrm{j}$ could be referring to some goats or cows known to the hearer. Tsvuku "the red one" mentioned earlier refers to the colour of a covert noun as well. It is this noun that qualifies the non-NP in the deep structure of the sentence. Such a position drives one into concluding that at surface structure level non-NPs can qualify to act as subjects in Shona due to the flexibility of the language but at the deep structure level only NPs perform the function.

\section{Conclusion}

It was found out that the general view that typical subjects are NPs is generally true to Shona as well. However, in cases where the subject constitutes some piece of old information, even non-NP entities may play the role both by their selves or in combination. The fact that the referent in such 
cases must be well known to the hearer demonstrates that in such sentences the non-NP subjects would only be a characteristic of the surface structure. At the deep structure level they have their deep structure NP subjects whose noun heads are omitted at the surface structure level due to the language' $\mathrm{s}$ flexibility and the desire to avoid repetition.

\section{References:}

Crystal, D. 1969. A Dictionary o Linguistics. Cambridge: Cambridge University Press.

Everaert, M.; van Riemsdijk, H.; Goedemans, R. (eds). 2006. The Blackwell Companion to Syntax, Volumes I - V. London: Blackwell.

Fortune, G. 1959. "A Preliminary Survey of Bantu Languages of the Federation," In Communication No. 14. Lusaka: The Rhodes Livingstone Institute.

Guthrie, M. 1948. The Classification of the Bantu languages. London: Oxford University Press for the International African Institute.

Langacker, R.W. 1991. Foundations of Cognitive Grammar: Vol. 2: Descriptive Application. Stanford: Stanford University Press.

Lee, B.D. 1974. “The Semantics of Inibalo Verbal Affixes.” In Lingua 34, p.181-218. Cambridge, Mass: MIT Press.

Mhute, I. and Kadenge, M. 2014. "Subcategories of the Shona Subject Relation," In Mediterranean Journal of Social Sciences Vol.5 No.27.

Mutasa, D. 1996. "The problems of standardizing spoken dialects: the Shona experience,” In Language Matters Vol.27, No.79.

Owens, M. 2004. "Grammatical Relations: A functionalist Perspective," In Language Vol.80 No.1. 